\title{
Physical Disability versus Developmental Disability
}

\author{
Hilda Aboagyewaa Agyekum* \\ Department of Social Work, Ghana
}

*Corresponding author: Hilda Aboagyewaa Agyekum, Department of Social Work, Ghana.

Received Date: November 13, 2018

Published Date: November 26, 2018

\begin{abstract}
Disability has been part of society from time begun, however, the study sorted out to inquire what exactly people thought about physical disability as well as developmental disability. The study made participants think along the lines of the perspectives they had about the two disorders and brought out the differences they had about them. This study was conducted in the Abelemkpe and Dzorwulu vicinity where participants were selected based on their convenience. The study was developed from a qualitative methodology and semi structured interview guides were used. Form the study it was brought to light that people were more accepting towards persons with developmental disabilities as compared to persons with developmental disabilities. They also made comparisons on the demandingness and caregiving both needed, education and job prospects.
\end{abstract}

\section{Introduction}

Over the years the idea of physical disability has been part of society that people tend to associate more with this type of disability as compared to developmental disabilities. In Ghana though disability in general is frowned on, it looks like people are more in tune with physical disabilities. Three percent of Ghanaians are classified as Persons with Disability. Generally, the percentage of females (3.1\%) with disability is slightly higher than males $(2.9 \%)$. There are more Persons with Disabilities in the rural areas compared to the urban centers. Disability represents a complex process and is not a single, static state. It refers to the outcome of the interaction of a person and his or her environment (physical, social, cultural or legislative) and represents a measure of the negative impact of environmental factors on one's ability to participate. Ginsburg F, et al. [1] are of the view that disability is not simply lodged in the body, but created by the social and material conditions that "dis-able" the full participation of a variety of minds and bodies. They explained that, an individual is disabled because the environment in which he finds himself does not have the favorable conditions needed for him to life a fulfilling and comfortable life. Thus, if societies create an enabling environment, there will be no disables in the world. An instance is the inclusion of wheelchair users in public life, which has led to an aspect of universal design that is fundamental to a fully democratic built environment $[2,3]$. The complexity of the concept has resulted in the proliferation of statistics on disability that are neither comparable nor easy to interpret [4] and that demand definitions that are flexible but able to capture disability in various manifestations [5].

The Centers for Disease Control and Prevention has set a definition for developmental disorders as "a group of conditions due to impairment in physical, learning, language, or behavioral areas." They went on to state that these disorders cause the individuals living with them many difficulties in certain areas of their life, especially in language, mobility, learning self-help and independent living. Though these disorders have been in existence for a long time, Armbrester ME is of the assertion that it was not until 1952 that Civitans (an association of community service clubs based in Birmingham, Alabama) adopted services for developmental disorders, which included workshops for special education teachers and day camps for children with disabilities. The publication of the works of Wolfensberger $\mathrm{W}$ can be said to be the first move towards the widespread adoption of the social model of disability $[6,7]$.

According to Boyle CA et al. [8] one in every six children in the United States has a developmental disability, with it having a greater chance of occurring in males than in females, though not the case in Ghana. The prevalence of these disorders in the western countries led to a research on its prevalence in Africa by Bakare MO, et al. [9] which resulted in the findings that the disorders is widespread though it is on a minimal in Africa. The causes of developmental 
disabilities are varied and remain unknown in a large proportion of cases [10-12], Finucane B, et al. [13] attributed this to the relative contribution of nature versus nurture being debated on for decades. However a few researchers have come out to say that the disorder can be from either small [14] or extreme environmental stress [15], genetic factors [11] and others address the spiritual causation [16]

On the other hand, Chiteraka C [17] has defined physical disability as any physiological disorder or condition, cosmetic disfigurement, or anatomic loss affecting one or more of the following body systems: neurological, musculoskeletal, lymphatic, skin, and endocrine systems. It is simply a limitation on an individual's physical functioning, mobility, dexterity or stamina. It is currently estimated that out of the ten percent of the world's population afflicted with various forms of impairments, about 500 million are physically impaired [18]. In Ghana, the 2010 population Census revealed that physical impairment was the second most common type of disability in Ghana after visual impairment in both urban (25.1\%) and rural (25.7\%) localities in Ghana.

Though a lot of work has been done on both physical disabilities and developmental disorders, there has not been much work done on the perspectives people have about them. It can be seen that in as much as everyone had their opinions on both disorders, there was the need to verify their stands on these disorders when asked to compare them. The study sorted out to investigate the ideologies of Ghanaians when it comes to physical and developmental disorders and how these two disorders are treated differently, or if they both receive the same the same kind of treatment in Ghana.

\section{Method}

The current study is designed to have a qualitative background. The study developed a semi-structured instrument as a guide in the data collection process. Each interview spanned between thirty to forty minutes. The study was conducted in the Greater Accra region of Ghana. The locality the study focused on was Abelemkpe and Dzorwulu. This study area was selected based on its blend of literates and illiterates. A total number of thirty participants were interviewed for the purpose of this research. Fifteen of the participants were employed in the formal sector while the other half was employed in the informal sector. The formal sector in this study refers to persons in jobs with normal working hours and regular wages, where as those in the informal sector refer to participants who did their own petty trade. Twenty five of the participants have had formal basic education, fifteen have had education to the tertiary level and twelve have vocational skills training and three have never had any education at all. The ages of the participants ranged from twenty six to fifty. To ensure gender representation, nineteen females and eleven males were interviewed.

\section{Results}

\section{Acceptance}

From the study, most people were more familiar with physical disability and more accepting towards it as compared to developmental disability. There were participants who said they would prefer a child with physical disability to a child with a developmental disability. They went on to explain that, with a physical disability there is always a way of getting the child to be comfortable and adapt well to the society which is not the case with a child with developmental disability.

Some participants were of the view that having a child with a developmental disability was more appalling than a child with a physical disability. There were some who were of the opinion that Ghanaians have come to terms with children with physical disabilities but not with developmental disability. They went on to explain that, when you have a child with a physical disability others tend to find you pitiful but a child with a developmental disability is seen to be abnormal.

\section{Job prospects}

Another concern that was raised in this regard was the job prospects of the two disabilities. Participants were of the view that it would be much easier to get a job if you have a physical disability than a developmental disability. They acknowledged the fact that getting a job was not easy in Ghana however, from their opinions; it would be much difficult for persons with developmental disabilities than those with physical disabilities.

\section{Demandingness and caregiving}

When participants were asked their views on how stressful taking care of a child with disability will be, they were of the view that parents with children with developmental disabilities would face more stress when it comes to the upbringing of their children as compared to those with physical disability. They talked about the fact that taking care of a child with a physical disability will get better and less stressful as he grows but that cannot be said of a child with a developmental disorder.

They made contributions on the stress level of parents with children with physical disabilities reducing whereas the same cannot be said for those with developmental disorders. Some participants were of the view that children with developmental disabilities might need help throughout their lives whiles those with physical disabilities will be able to take care of themselves with time.

The issue of persons with disability being able to take care of them also sprung up in the study. They were of the view that persons with physical disabilities are able to adapt quickly to their situation as compared to those with developmental disabilities. They commented that a child with physical disability was more likely to take care of himself than a child with developmental disability.

\section{Education}

The issue on the kind of education children with disabilities get also came up during interview sessions. It was realized that participants attested to the fact that educating persons with disabilities is difficult. However, following the same trend, it was seen to be much easier with persons with physical disabilities than those with developmental disabilities. They brought out the fact that the former can attend a mainstream school whiles the later will have to be in the special schools. 
One participant commented that now when you mention special children all people think about is children with developmental disability. Some participants commented that there was no need to educate persons with developmental disabilities.

Participants brought up the fact that education will be much more expensive for children with physical disabilities than those of children with developmental disability. They brought up the issue of differences in mainstream and special schools. They added on that the differences in curriculum would lead to increase in cost for special schools.

The difference in curricular was also an issue participants with higher learning came out with. They stated that persons with physical disabilities are able to attain the highest level of education they need whiles those with developmental disability usually would have to end up with vocational skills instead of attaining higher education. They commented that even if they were trained hardly would you see them use it to work, whereas a lot of persons with physical disabilities are always seen engaged in different productive ventures.

\section{Discussion}

Though both disabilities limits the individual involved, this study is geared towards the individual being better off with a physical disability than a developmental one. Though the cause of developmental disorders is unknown, that of physical disorders is known making the later an easier predicament to understand. Bizier C, et al. [19] are of the view that, discrimination of persons with developmental disabilities start from childhood, since they do not get to interact with other children without disabilities, hence missing out on the social life of mainstream schools. Participants in the study were of the view that though both disorders are discriminated on, it is on a low when it comes to physical disabilities. They commented that people are used to seeing persons with physical disability and seeing them draws sympathy from the observer, however, children with developmental disabilities are seen as a curse and all measures to avoid getting in touch with them are put in place.

People with developmental disabilities have cognitive and developmental deficits [20] whereas persons with physical disabilities do not; this was an issue that came up during the job prospects and education for persons with disabilities. Participants were of the view that, due to the low intellectual capacity of persons with developmental disorders, getting a job would be much difficult as compared to those with physical disabilities. They did not dispute the fact that getting jobs in Ghana when you are physically challenged is very difficult, but said that employees when asked to select between a person with a physical disability and that of a person with a developmental disorder will definitely select the former. Courcy I, eta al. [21] is of the view that even if persons with developmental disabilities are educated, they still will not be able to put it to use because of their mental capacity.

Bizier, et al. [19] asserted that adults with developmental disorders are four times more likely not to have completed high school with three times lower not be engaged in any type of employment. Participants in this study accentuated this point by saying that persons with developmental disorders are less likely to be educated as compared with those with physical disabilities. They were of the opinion that, children with physical disabilities can join mainstream schools and attain the highest level of education they want which cannot be said of children with developmental disabilities. They are of the opinion that those with developmental disorder can best learn vocational skills and even with that it takes a longer period than a child without disabilities. There are comments about people not wanting to patronize their services even if they are able to learn the vocation.

It is stipulated that, having a child with developmental disorder stresses the family as a whole, with the child's demandingness and neediness for care having to do with maternal stress, the child's acceptability relating more to paternal stress [22] and the stigma attached to the illness also relating more to the siblings' stress [23]. A large amount of research has shown that, behavioral problems of the child with the disorder are a major factor affecting stress in parents [24]. With this as a backbone, the participants of this study were drawn towards the conclusion that taking care of a child with developmental disabilities would be much more stressful as compared to a child with developmental disabilities. They commented that, as time goes on, a child with a physical disability would be able to look after him or herself whereas a child with developmental disability will need help even with their basic needs.

\section{Acknowledgment}

I am grateful to God for making this study a success. I am immensely grateful to Mr. Vincent Macauley for his immerse contribution to the study. My appreciation also goes to all participants who took part in the study; this would not have been a success without you.

\section{Conflict of Interest}

Author declare no conflict of interest.

\section{References}

1. Ginsburg F, Rapp R (2013) Disability worlds. Annual Review of Anthropology 42: 53-68.

2. Crews DE, Zavotka S (2006) Aging, disability, and frailty: implications for universal design. J Physiol Anthropol 25(1): 113-118.

3. Friedner M, Osborne J (2013) Audit bodies: embodied participation, disability universalism, and accessibility in India. Antipode 45(1): 4360 .

4. Madans JH, Loeb ME, Altman BM (2011) Measuring disability and monitoring the UN Convention on the Rights of Persons with Disabilities: the work of the Washington Group on Disability Statistics. In BMC public health 11 Suppl 4: S4.

5. Loeb ME, Eide AH, Mont D (2008) Approaching the measurement of disability prevalence: the case of Zambia. ALTER-European Journal of Disability Research/Revue Europeenne de Recherche sur le Handicap 2(1): $32-43$

6. Armbrester ME (1992) The Civitan Story. Birmingham, AL (Ed): Ebsco Media, pp 74-75.

7. Wolfensberger W (1975) The origin and nature of our institutional models. Human Policy Press. 
8. Boyle CA, Boulet S, Schieve LA, Cohen RA, Blumberg SJ, et al. (2011) Trends in the prevalence of developmental disabilities in US children, 1997-2008. Pediatrics 127(6): 1034-1042.

9. Bakare MO, Agomoh AO, Ebigbo PO, EatonJ, Okonkwo KO, et al. (2009) Etiological explanation, treatability and preventability of childhood autism: a survey of Nigerian healthcare workers' opinion. Annals of General Psychiatry 8(1): 6.

10. Speaks A (2011) What is autism? Retrieved on November 17.

11. Szatmari P (2003) The causes of Autism Spectrum Disorder. BMJ 326(7382): 173-174

12. Wakefield, AJ, Murch SH, Anthony A, Linnell J, Casson DM, et al. (1998) RETRACTED: Ileal-lymphoid-nodular hyperplasia, non-specific colitis, and pervasive developmental disorder in children 351(9103): 637-641.

13. Finucane B, Abrams L, Cronister A, Archibald AD, Bennett RL, et al. (2012) Genetic counseling and testing for FMR1 gene mutations practice guidelines of the national society of genetic counselors. J Genet Couns 21(6): 752-760.

14. Payne K J, Ross LM (2010) Simplicity parenting: Using the extraordinary power of less to raise calmer, happier, and more secure kids. Ballantine Books.

15. Perry BD, Szalavitz M (2007) The Boy Who Was Raised as a Dog: And Other Stories from a Child Psychiatrist's Notebook-What Traumatized Children Can Teach Us about Loss, Love and Healing. Basic Books.
16. Agyekum HA (2018) The views and knowledge of parents of children with autism spectrum disorder. Journal of Child and Adolescent Psychiatry 2(2).

17. Chitereka C (2010) People with disabilities and the role of social workers in Lesotho. Social Work \& Society 8(1): 82-93.

18. Ghana. Statistical Service (2013) 2010 Population \& Housing Census: National Analytical Report. Ghana Statistics Service.

19. Bizier C, Fawcett G, Gilbert S, Marshall C (2015) Developmental disabilities among Canadians aged 15 years and older.

20. Baron Cohen S, Leslie AM, Frith U (1985) Does the autistic child have "theory of mind"? Cognition 21(1): 37-46.

21. Courcy I, Des Rivieres C (2017) "From cause to cure": A qualitative study on contemporary forms of mother blaming experienced by mothers of young children with autism spectrum disorder. Journal of Family Social Work 20(3): 233-250.

22. Keller D, Honig AS (2004) Maternal and paternal stress in families with school-aged children with disabilities. Am J Orthopsychiatry 74(3): 337348.

23. Nartey Stella (2013) Perception of Stigma on the Psychological Wellbeing of Siblings of Children with Intellectual Disability PhD diss, University of Ghana.

24. Hastings RP (2002) Paternal stress and behavior problems of children with development disability. Journal of Intellectual and Developmental Disability 27(3): 149-160. 